\title{
Postural control in standing among adolescents with Idiopathic Scoliosis Liat Meller-Gattenyo
}

\author{
Address: University of Haifa, Occupational Therapy (Physiotherapy), Haifa, Israel \\ from $5^{\text {th }}$ International Conference on Conservative Management of Spinal Deformities \\ Athens, Greece. 3-5 April 2008 \\ Published: 15 January 2009 \\ Scoliosis 2009, 4(Suppl I):O22 doi:I0.I I86/I748-7|6I-4-SI-O22
}

This abstract is available from: http://www.scoliosisjournal.com/content/4/SI/O22

(C) 2009 Meller-Gattenyo; licensee BioMed Central Ltd.

\section{Background}

Intact posture enables postural control (PC) and balance during standing. We assumed that differences in PC would be found between patients suffering from Adolescent Idiopathic Scoliosis (AIS) and a matched control group without postural disorders.

\section{Aim}

The purpose of this study was to compare standing balance between adolescents suffering from AIS and a control group.

\section{Methods}

Twenty AIS patients, aged 10-18 from both sexes and twenty matched control group patients participated in the study. Balance in eight postural positions was measured in standing with open and closed eyes on a firm or a foam surface, standing on one foot \& standing while rotating the trunk. Dependent variables were body sway and weight distribution on and between feet, in sagittal and frontal planes.

\section{Results}

Significant differences between the two groups were found in weight bearing on the foot in standing with eyes closed and on the single left foot stance. Significant differences were also demonstrated between the sexes in six testing positions. Scoliosis severity was significant in five positions, as well as the percentage of heel weight bearing in three positions. In all positions the AIS group had higher postural sway values than the control group. The latter was not found to be statistically significant. A positive correlation between scoliosis severity, body movements and heel weight distribution was found.

\section{Conclusion}

Postural control and balance in static posture positions among adolescents suffering from AIS was decreased compared to the control group. The male adolescents demonstrated inferior posture control compared to the females in the same group, and to the males in the control group.

Current therapeutic methods should be analyzed, and new methods should be developed considering these aspects. Future research should include different disciplines to better assess posture control.

\section{References}

I. Guo X, Chau WW, Hui-Chan CW, Cheung CS, Tsang WW, Cheng JC: Balance control in adolescents with idiopathic scoliosis and disturbed somatosensory function. Spine 31(14):E437-40. 2006 Jun 15; 